\title{
A INTRAUTERINE GROWTH RESTRICTION MODEL IN PREGNANT RABBIT PRODUCES NEONATAL NEUROBEHAVIOURAL IMPAIRMENT
}

\author{
E. Eixarch ${ }^{1}$, M. Illa ${ }^{1}$, F. Figueras ${ }^{1}$, V. Tenorio ${ }^{2}$, E. Gratacos ${ }^{1}$ \\ ${ }^{1}$ Department of Maternal-Fetal Medicine, ${ }^{2}$ Department of Neonatal Medicine, Hospital Clinic-University of \\ Barcelona, IDIBAPS and CIBER-ER, Barcelona, Spain
}

Objective: To assess the existence of differences in neonatal neurobehaviour in a rabbit model of intrauterine growth restriction (IUGR).

Material and methods: A IUGR model was created in 18 pregnant rabbits in which $40-50 \%$ of the uteroplacental vessels of one horn were ligated at 25 days of gestation and contralateral horn were considered as control. Cesarean section was performed at 30 days (term 31 days). After delivery, neonatal weight was recorded in living newborns. At postnatal day +1 , neonates were assessed by means of validated neurobehavioural test including evaluation of tone, spontaneous locomotion, responses to olfactory stimuli, and coordination of suck and swallow.

Results: Mortality rate was significantly increased in cases (35.1vs11.1\%,p<0,001). When compared with controls, IUGR showed significantly lower birthweight $(33.9 \pm 9.8 \mathrm{vs} 45.9 \pm 8.2, \mathrm{p}<0,001)$. Regarding neurobehavioural test, cases showed significantly worst performance in almost all parameters (Table)

Conclusion: IUGR by means of selective ligature of uteroplacental vessels results in impaired neonatal neurobehaviour performance. This surgical model could be useful to investigate the effects of placental insufficiency on brain development.

\begin{tabular}{|l|l|l|l|}
\hline & control $\mathrm{n}=20$ & IUGR $\mathrm{n}=23$ & $\mathrm{p}$ \\
\hline $\begin{array}{l}\text { Righting reflex , number } \\
\text { of turns }\end{array}$ & $8.9(1.3)$ & $6.6(3.0)$ & 0.003 \\
\hline $\begin{array}{l}\text { Lineal movement, line } \\
\text { crosses in 60 sec }\end{array}$ & $2.1(1.5)$ & $1.3(1.2)$ & 0.082 \\
\hline \hline Odour test time, seconds & $4.2(1.5)$ & $7.1(3.6)$ & 0.012 \\
\hline Posture, score & $3.0(0)$ & $2.57(0.7)$ & 0.006 \\
\hline Tone, score & $4.0(0.2)$ & $3.1(0.8)$ & $<0.001$ \\
\hline Locomotion, score & $2.7(0.6)$ & $2.0(0.8)$ & 0.001 \\
\hline $\begin{array}{l}\text { Sucking and swallowing, } \\
\text { score }\end{array}$ & $2.7(0.7)$ & $1.9(0.9)$ & 0.004 \\
\hline
\end{tabular}

[Neurobehavioural test results (mean(sd))] 